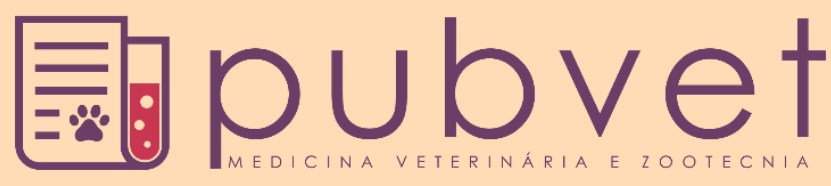

https://doi.org/10.31533/pubvet.v13n11a460.1-9

\title{
Demodiciose em gatos domésticos: revisão
}

\author{
Marilia Avila Valandro ${ }^{1 *} \bullet$, Rochelle Gorczak ${ }^{1} \bullet$ \\ ${ }^{l}$ Professora do Centro Universitário Ritter dos Reis - UniRitter, Faculdade de Medicina Veterinária, Porto Alegre-RS, Brasil. \\ *Autor para correspondência, E-mail: mavalandro@gmail.com
}

Resumo. A demodiciose é considerada incomum na dermatologia em felinos. Em contrapartida, em cães, é uma das alterações cutâneas mais frequentemente atendidas na clínica de pequenos animais. Pode ser causada pelo ácaro Demodex cati ou pelo D. gatoi e tem sido reportado envolvimento de ácaros ainda não nomeados. Diferentes técnicas de diagnóstico e tratamento têm sido estudados recentemente principalmente para a caninos, porém, existem poucos estudos atuais sobre o tema em felinos, e, dessa forma, esta revisão bibliográfica tem por objetivo realizar um compilado acerca dessa dermatopatia, descrevendo sua epidemiologia, apresentações clínicas, diagnóstico e opções terapêuticas atuais, pois como se sabe, a população felina doméstica está em ascensão nos últimos anos, e há a tendência de aumento da casuística de atendimentos de dermatopatias nessa espécie, em especial a demodiciose.

Palavras chave: Demodex, dermatopatia, diagnóstico, felino, tratamento

\section{Demodicosis in domestic cats: review}

Abstract. Demodiciosis is considered uncommon in feline dermatology. By contrast, in dogs, it is one of the most frequently seen skin changes in small animal clinics. It may be caused by the Demodex cati mite or D. gatoi and involvement of unnamed mites has been reported. Different diagnostic and treatment techniques have been recently studied, especially for canines, however, there are few current studies on the subject in felines, and thus, this literature review aims to compile this dermatopathy, describing its epidemiology, presentations. Current clinical, diagnostic and therapeutic options, as it are known that the domestic feline population has been on the rise in recent years, and there is a tendency to increase the number of dermatopathic care cases in this species, especially demodiciosis.

Keywords: Demodex, dermatopathy, diagnosis, feline, treatment

\section{Demodicosis en gatos domésticos: revisión}

Resumen. La demodicosis se considera poco común en dermatología felina. Por el contrario, en perros, es uno de los cambios cutáneos más frecuentes en clínicas de animales pequeños. Puede ser causado por el ácaro Demodex cati o D. gatoi y se ha informado de la participación de ácaros no identificados. Recientemente se han estudiado diferentes técnicas de diagnóstico y tratamiento, especialmente para los caninos, sin embargo, hay pocos estudios actuales sobre el tema en felinos y, por lo tanto, esta revisión de literatura tiene como objetivo recopilar información sobre esta dermatopatología, describiendo su epidemiología, presentaciones clínicas, diagnósticas y opciones terapéuticas actuales, ya que se sabe que la población felina doméstica ha ido en aumento en los últimos años, y existe una tendencia a aumentar el número de casos de atendimientos dermatológicos en esta especie, especialmente la demodicosis.

Palabras clave: Demodex, dermopatía, diagnóstico, felino, tratamiento 


\section{Introdução}

A demodicose felina é uma condição parasitária incomum que afeta a pele dos gatos (Ortúñez et al., 2009); porém, emergente (Ortúñez et al., 2009). A prevalência relatada é de aproximadamente quatro casos a cada 10.000 gatos (Bizikova, 2014). Pode ser causada pelo ácaro Demodex cati ou pelo D. gatoi e tem sido reportado envolvimento de ácaros ainda não nomeados (Beale, 2012; Löwenstein et al., 2005; Ortúñez et al., 2009). O D. cati possui morfologia similar aos $D$. canis e também reside nos folículos pilosos, glândulas e ductos sebáceos (Beale, 2012; Ortúñez et al., 2009). Também é considerado como parte da fauna normal da pele, mesmo que não foi estabelecido se está presente em todos os gatos saudáveis, ou apenas em uma subpopulação específica (Ferreira et al., 2015). Já o D. gatoi tem sido mais descrito em felinos, e sua morfologia consiste em um corpo largo e curto, e o ácaro localiza-se no estrato córneo, e é considerado um parasita contagioso, que pode ser transmitido entre gatos e provavelmente entre outras espécies (Saari et al., 2009).

A ocorrência de demodiciose por $D$. cati é atribuída à imunossupressão, e o surgimento desse quadro clínico resulta do aumento da população do ácaro (Beale, 2012; Frank et al., 2013; Löwenstein et al., 2005). Os principais sinais clínicos relatados são alopecia e escoriações, e as lesões normalmente se localizam em cabeça e pescoço (Beale, 2012; Bizikova, 2014; Löwenstein et al., 2005). O principal sinal clínico associado às infestações por $D$. gatoi é o prurido, que geralmente se manifesta como excesso de higiene (Beale, 2012).

O diagnóstico é baseado no histórico, exame físico e visualização microscópica do ácaro em raspados de pele (Beale, 2012; Bizikova, 2014), tricogramas, fita adesiva (Silbermayr et al., 2013), esfregaços de swabs óticos (Van Poucke, 2001), biópsias de pele (Carlotti, 2006), flotação fecal (Silbermayr et al., 2013) e resposta a tratamentos acaricidas (Ortúñez et al., 2009).

O tratamento sempre engloba a realização de avaliação das condições gerais do paciente, na busca do fator imunossupressor, o qual deve ser devidamente tratado. As opções terapêuticas são diversas, e incluem o uso de acaricidas de diferentes classes (Beale, 2012; Bizikova, 2014; Duangkaew \& Hoffman, 2018; Löwenstein et al., 2005; Matricoti \& Maina, 2017).

Este trabalho tem por objetivo realizar uma revisão de literatura acerca da demodiciose em gatos domésticos, descrevendo a epidemiologia, apresentações clínicas e opções terapêuticas, com base em estudos atuais sobre o tema.

\section{Revisão de literatura}

\section{Epidemiologia e Patogenia}

A demodiciose felina é uma dermatopatia parasitária que afeta essa espécie com menos frequência do que é observado em cães (Beale, 2012; Ortúñez et al., 2009), sendo considerado, portanto, de rara ocorrência. A sintomatologia é variada, e parecem depender de acordo com a espécie de ácaro envolvido, embora tenham sido relatados casos em que há o envolvimento de mais de uma espécie (Beale, 2012).

Ácaros do gênero Demodex são comumente encontrados nos folículos pilosos e glândulas sebáceas de vários mamíferos e são considerados espécie-específicos, e muitas vezes não causam doença clínica (Ferreira et al., 2015). Entretanto, se o ambiente cutâneo do hospedeiro facilita sua proliferação, se tornam parasitas, causando a demodiciose clínica, geralmente associada a doenças imunossupressoras (Lacey et al., 2011; Miller et al., 2013). Em felinos, 3 espécies de Demodex foram descritas, D. cati, D. gatoi e uma espécie ainda não nomeada (Beale, 2012; Ferreira et al., 2015), que difere morfologicamente das demais (Beale, 2012; Löwenstein et al., 2005). O D. cati (Figura 1) possui morfologia similar ao D. canis, é um ácaro longo e fino, e também reside nos folículos pilosos, glândulas e ductos sebáceos (Beale, 2012; Ortúñez et al., 2009), podendo induzir foliculite, piodermite, hiperemia, alopecia, descamação e linfoadenopatia regional (Foley, 1995). Acredita-se que, assim como ocorre nos cães, o D. cati é transferido da mãe para os neonatos durante o período de lactação ( (Desch Juniorr \& Stewart, 1999; Iliev et al., 2019). Poucos estudos conseguiram provar a presença de Demodex em animais saudáveis. Em um estudo de prevalência de D. canis em cães clinicamente saudáveis, o ácaro DNA foi amplificado na maioria de animais estudados, concluindo que o $D$. canis é um habitante normal da pele nos cães, como parece ocorrer em muitos outros mamíferos (Lacey et al., 2011); porém, não comprovado em felinos (Ferreira et al., 2015). 
A ocorrência de demodiciose por $D$. cati geralmente está correlacionada a doenças sistêmicas que cursam com comprometimento imunológico (Frank et al., 2013) e, por esse motivo, os pacientes afetados devem ser avaliados para descartar infecções retrovirais, entre outros (Beale, 2012). Dentre as causas de imunossupressão descritas estão à infecção crônica do trato respiratório superior, alopecia endócrina felina, lúpus eritematoso sistêmico, toxoplasmose (Hnilica \& Medleau, 2012; Medleau et al., 2003), tratamentos imunossupressivos (Bizikova, 2014; Ortúñez et al., 2009), diabete mellitus, hiperadrenocorticismo, afecções cutâneas imunomediadas (Foley, 1995) vírus da leucemia felina (FeLV), vírus da imunodeficiência felina (FIV) (Beale, 2012; Foley, 1995; Pereira et al., 2005), verminoses intestinais mistas como Spirometra mansonoides, Trichuris sp. e Ancylostoma sp. (Valandro et al., 2016) e neoplasias como carcinoma de células escamosas (Guaguère et al., 1999). Todavia, alguns felinos com infestação por $D$. cati não apresentem patologias subjacentes ou históricos de uso de drogas imunossupressoras (Beale, 2012).

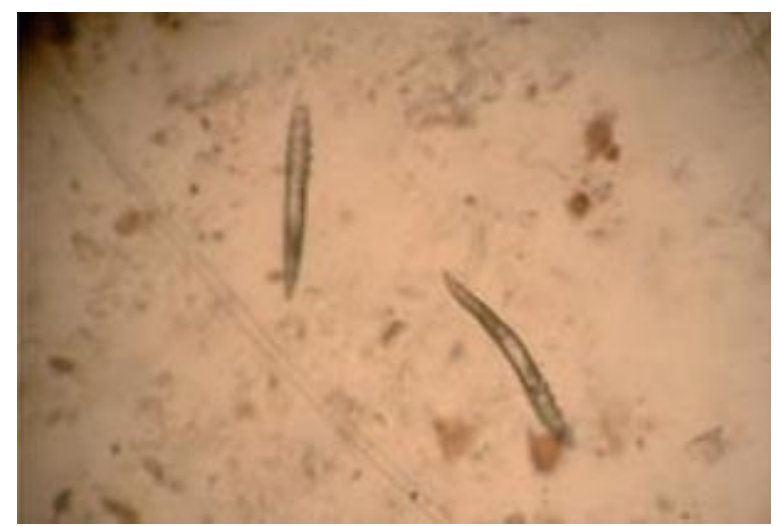

Figura 1. Demodex cati adultos (x10). Fonte: Ortúñez et al. (2009).

Já sobre o D. gatoi (Figura 2) pouco se conhece de sua biologia ou o modo de transmissão, patogênese ou opções de tratamento (Saari et al., 2009). E, ainda, pouco se conhece a respeito da patogenia (Ortúñez et al., 2009), embora pareça ser o ácaro mais comum das espécies descritas em felinos. Sua morfologia consiste em um corpo largo e curto, que vive no estrato córneo (Beale, 2012). É considerado um parasita contagioso, que pode ser transmitido entre gatos e provavelmente outras espécies (Saari et al., 2009). Acredita-se na existência de portadores assintomáticos, nos quais o ácaro está presente em grande número já que, por não induzir prurido, os gatos não eliminam com a lambedura (Silbermayr et al., 2013). Em contraste com a infestação por D. cati, o D. gatoi não parece estar associado a doenças concomitantes ou imunossupressão na maioria dos casos. Em alguns animais pode ocorrer hipersensibilidade ao $D$. gatoi, que se reflete com um grau importante de prurido mesmo com a presença de poucos ácaros (Beale, 2012).
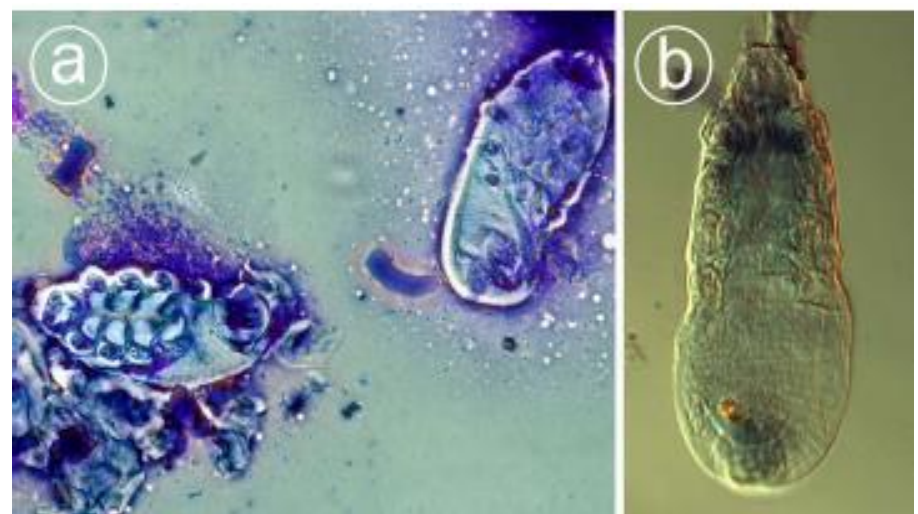

Figura 2. D. gatoi visualizado em microscopia. A coloração de MayGrünwald-Giemsastained, demonstrando um ácaro adulto (A) e um estágio ninfal (B). O material azulado escamoso em volta os ácaros são queratina. BD. gatoi adulto não corado. Fonte: Saari et al. (2009). 
Vários estudos descrevem a presença de ácaros Demodex em gatos, que diferem morfologicamente do D. cati e do D. gatoi (Figura 3) (Beale, 2012; Kano et al., 2012; Löwenstein et al., 2005; Moriello, 2014; Silbermayr et al., 2013). A descrição morfológica desse ácaro descreve-o como sendo menor que o $D$. cati e maior que o $D$. gatoi, além de ter um corpo mais arredondado que o $D$. cati e mais fino que o D. gatoi (Löwenstein et al., 2005). Ainda não foi possível estabelecer a relação entre os casos afetados por essa espécie à presença de doenças concomitantes (Beale, 2012; Kano et al., 2012; Löwenstein et al., 2005; Moriello, 2014; Silbermayr et al., 2013). Embora a sequência de DNA dessa espécie pareça ser diferente do $D$. cati e $D$. gatoi (Ferreira et al., 2015), ainda não foi estabelecido definitivamente se realmente são espécies geneticamente distintas ou apenas uma variação morfológica de uma etapa de desenvolvimento de espécies existentes (Moriello, 2014). Estudos filogenéticos mais recentes inclinamse à primeira possibilidade (Ferreira et al., 2015), e o nome temporário da nova espécie é D. felis (Silbermayr et al., 2013).

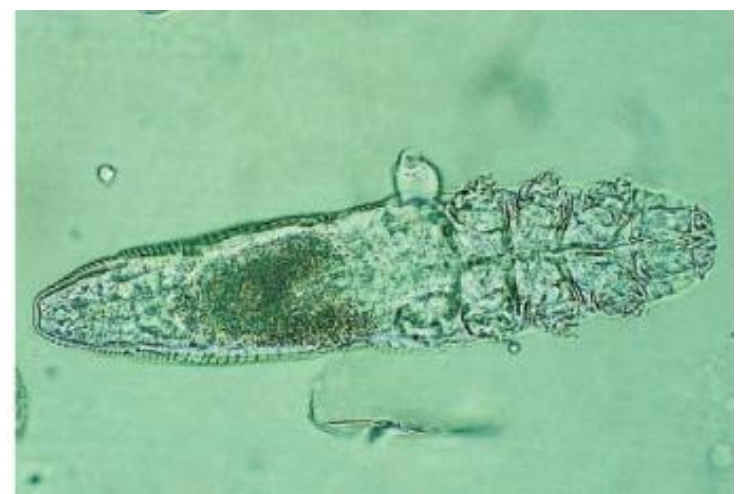

Figura 3. Fêmea adulta da espécie de Demodex não nomeada (x1000). Fonte: Löwenstein et al. (2005).

\section{Sinais clínicos}

As lesões incluem dermatite com diferentes graus de prurido, além de comedões, escamas, seborreia, pápulas e escaras (Ferreira et al., 2015). A forma localizada pode afetar a face e orelha (Beale, 2012), podendo ser a otite ceruminosa externa o único sinal clinicamente observado (Van Poucke, 2001). A idade inicial da doença é ampla e variável (Guaguère et al., 1999). Gatos siameses parecem estar predispostos (Neel et al., 2007). Os sinais clínicos mais observados em casos envolvendo o ácaro D. cati são alopecia e escoriação Ortuñez (Beale, 2012; Bizikova, 2014; Foley, 1995; Guaguère et al., 1999; Löwenstein et al., 2005; Ortúñez et al., 2009; Valandro et al., 2016) (Figura 4). Outros sinais também observados são de dermatite miliar (Figura 5), erosões, seborreia, comedões, pápulas e eritema (Beale, 2012; Guaguère et al., 1999; Matricoti \& Maina, 2017) (Figura 6 e 7). As lesões normalmente estão localizadas em cabeça e pescoço (Beale, 2012; Bizikova, 2014; Foley, 1995; Guaguère et al., 1999; Löwenstein et al., 2005; Ortúñez et al., 2009; Valandro et al., 2016).

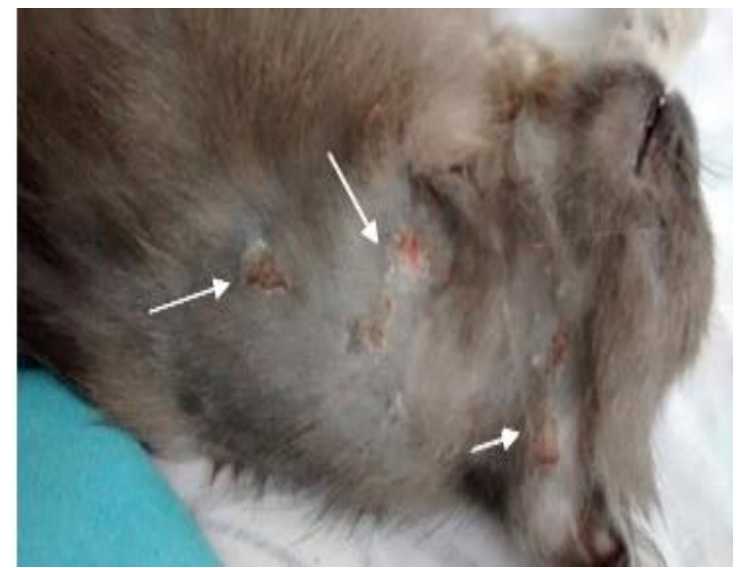

Figura 4. Alopecia e escoriações (setas) na região de cabeça e pescoço em um felino com demodiciose por D. cati. Fonte: Valandro et al. (2016). 


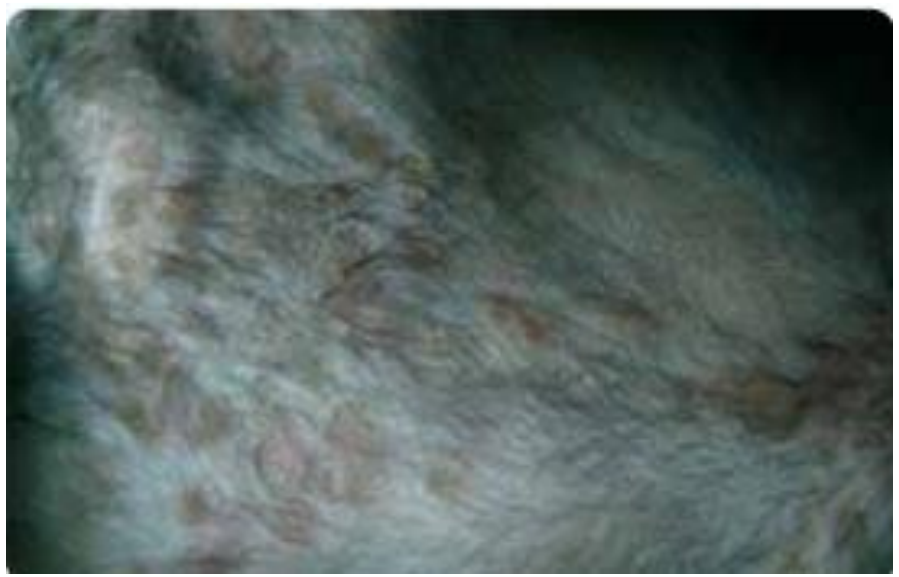

Figura 5. Dermatite miliar em um felino com demodiciose por $D$. cati. Fonte: Wolberg \& Blanco (2008).

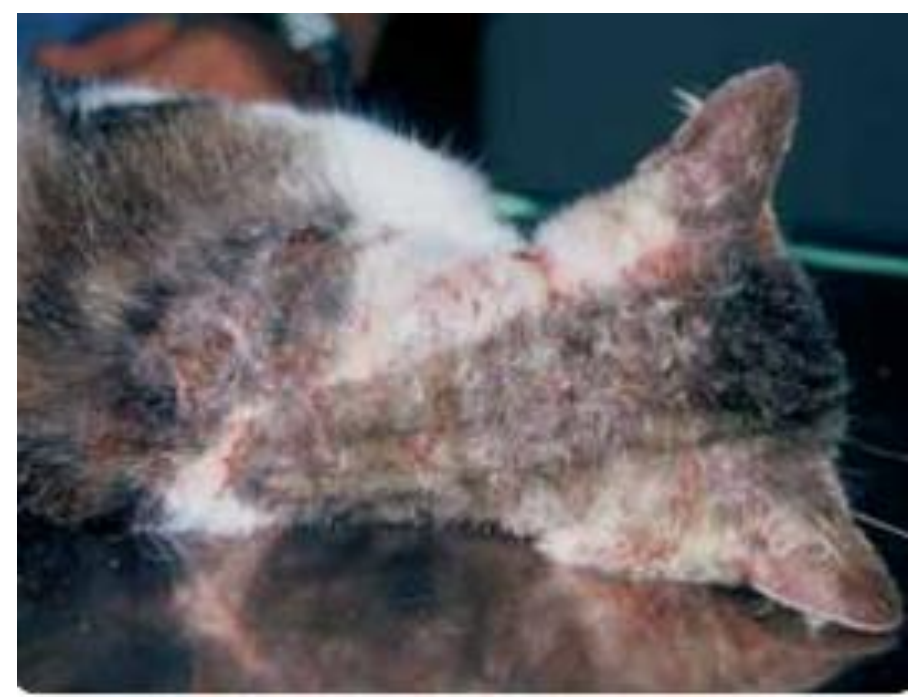

Figura 6. Alopecia, eritema e descamação na região de cabeça e pescoço em um felino com demodiciose por D. cati. Fonte: Wolberg \& Blanco (2008)

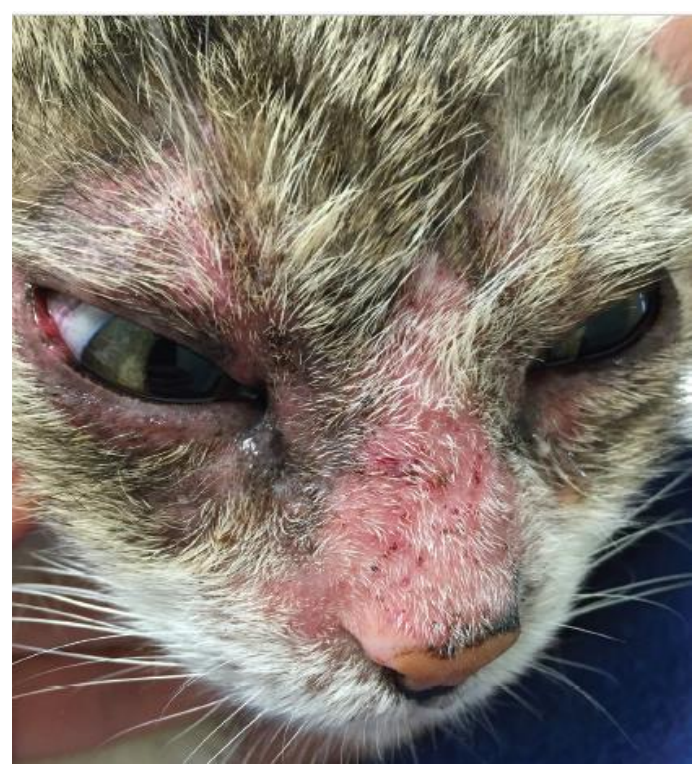

Figura 7. Alopecia, eritema e pápulas na região dorsal do plano nasal e periocular em um felino acometido por demodiciose generalizada por D. cati. Fonte: Matricoti \& Maina (2017). 
O principal sinal clínico associado a infestações por D. gatoi é o prurido, que geralmente se manifesta como um excesso de lambedura (Beale, 2012; Saari et al., 2009). Os pacientes geralmente apresentam alopecia auto induzida, e raramente dermatite é observada. Embora qualquer área do corpo possa ser afetada, o abdômen ventral, parte interna das coxas, flancos e os membros anteriores podem ser mais afetados, por serem áreas que podem ser lambidas com mais facilidade (Beale, 2012). Em casos mais graves, alopecia, crostas e escoriações auto-infligidas são observadas (Saari et al., 2009) (Figura 8). Ocasionalmente podem ser observadas dermatite miliar e úlceras labiais indolentes (Beale, 2012).
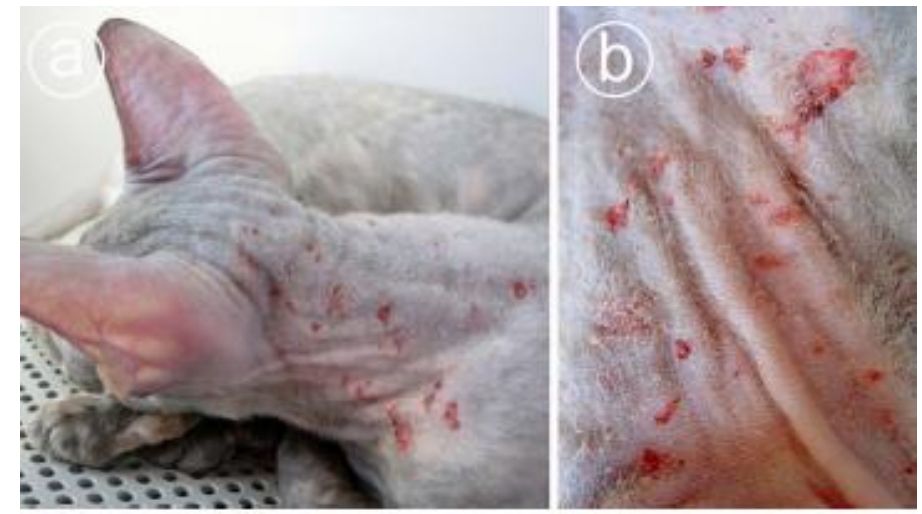

Figura 8. A- Alopecia, crostas e escoriações na região de cabeça e pescoço de um felino com demodicose por D. gatoi. B- Lesões aproximadas. Fonte: Saari et al. (2009).

Já nos casos em que há infestação pela espécie não nomeada, os sinais clínicos associados são variáveis, e incluem prurido de graus variados e alopecia, relacionados à depilação fácil (Figura 9) (Bernstein et al., 2014; Kano et al., 2012; Löwenstein et al., 2005; Moriello, 2014; Silbermayr et al., 2013).

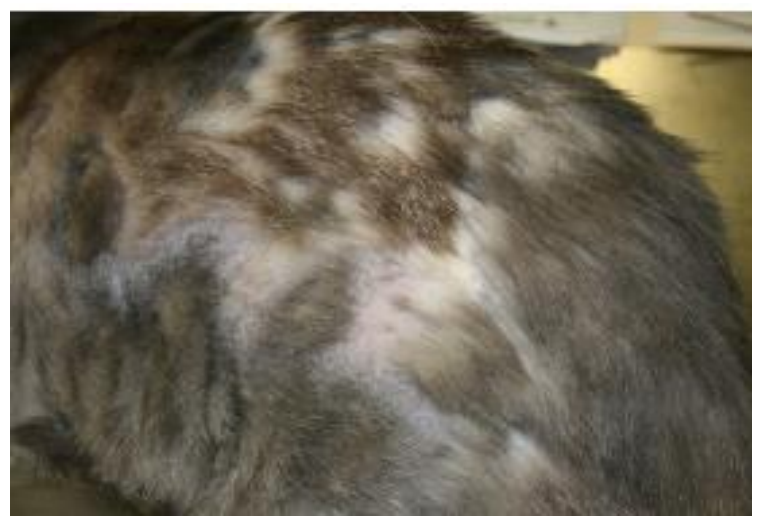

Figura 9. Lesões alopécicas em um felino com demodiciose causada pela espécie não nomeada. Fonte: Bernstein et al. (2014)

\section{Diagnóstico e diagnósticos diferenciais}

A demodiciose felina deve ser considerada em qualquer gato com hipotricose, alopecia simétrica e/ou prurido. No caso do D. cati, o diagnóstico é estabelecido com base na história, exame físico e visualização do ácaro na avaliação microscópica de raspagens de pele. Devido a sua localização folicular, a raspagem deve ser profunda o suficiente (produzir sangramento capilar) e é recomendada que se pressione a área antes para obter melhores resultados (Beale, 2012). Embora, na maioria dos casos, o ácaro é facilmente encontrado, por vezes, o seu número pode ser muito baixo, o que tornaria difícil a observação (Miller et al., 2013). Em casos de otite externa, devem ser realizados esfregaços com óleo mineral de amostras do cerúmen, e visualizados em microscópio (Van Poucke, 2001). Também podem ser encontrados ácaros nos folículos pilosos e/ou nas glândulas sebáceas, quando realizadas biópsias de pele, e, histologicamente, visualiza-se imagens de foliculite e furunculose (Carlotti, 2006). Em lesões localizadas com alto grau de inflamação, recomenda-se a realização de biópsias de pele, pois casos de infestação por $D$. cati concomitante com carcinoma de células escamosas in situ foram relatados 
(Guaguère et al., 1999). Os diagnósticos diferenciais incluem dermatofitose, pênfigo foliáceo, foliculite bacteriana, dermatite/otite por Otodectes, infestação por Notoedris cati, reações a medicamentos, dermatite alérgica e linfoma cutâneo (Beale, 2012).

O diagnóstico de D. gatoi é mais dificultoso, principalmente devido à sua localização superficial, o que nem sempre é fácil detectar em raspados de pele (Takle \& Hnilica, 2004), podendo ser facilmente removido através da lambedura. Nesses casos, se recomenda realizar diversos raspados superficiais, incluindo áreas não alopécicas, utilizando óleo mineral no bisturi ou diretamente na pele (Beale, 2012) e indica-se a realização de testes de fita adesiva e tricogramas. Em alguns casos, os ácaros são mais encontrados em pelos de áreas com certo grau de inflamação e a depilação seja mais fácil. Em situações em que há uma alta suspeita da doença e o ácaro não foi observado nas técnicas habituais, recomendase a realização de métodos de flutuação fecal, onde é possível a visualização do parasita (Silbermayr et al., 2013) ou avaliar a resposta ao tratamento com produtos acaricidas (Ortúñez et al., 2009). É fundamental obter amostras de todos os gatos contactantes, mesmo sem apresentar sintomatologia clínica (Beale, 2012). São frequentes resultados negativos nas raspagens devido ao fato de os felinos eliminarem os parasitas por lambedura (Silbermayr et al., 2013). Deve-se diferenciar de dermatofitose, alergias, outros ectoparasitas, principalmente Notoedres e Cheiletiella e alopecia psicogênica (Saari et al., 2009). Já a espécie não nomeada pode ser visualizada em exames microscópicos de pelos, obtidos de locais de fácil depilação, sendo observados ao longo da haste capilar, embora não tenha sido observado em biópsias de pele (Beale, 2012).

O uso de técnicas de diagnóstico moleculares mais sofisticadas, como o RT-PCR promete ser uma ferramenta bastante útil no futuro, o que permitirá, por meio da caracterização genética dos ácaros, alcançar uma abordagem diagnóstica e terapêutica bem-sucedida para cada caso (Bernstein et al., 2014).

\section{Tratamento e prognóstico}

Nas últimas décadas, muitas pesquisas estão sendo realizadas para o desenvolvimento de novos produtos para o tratamento da demodiciose felina e canina. Os primeiros estudos trazem a utilização de ivermectina (0,2-0,3 mg/kg, via oral, a cada 24/48 horas) (Beale, 2012; Löwenstein et al., 2005), doramectina (600 $\mathrm{mcg} / \mathrm{kg}$, subcutâneo, semanalmente, 2-3 doses) (Johnstone, 2002), banho semanal, durante 2-3 semanas com amitraz na concentração de 0,0125 a 0,025\% (Löwenstein et al., 2005; Saari et al., 2009), ou com cal de enxofre na concentração de 1,6-2\%. Todavia as principais limitações do uso da ivermectina são sinais de intoxicação, com alterações no sistema nervoso central, além de não ser efetiva para o tratamento da espécie não nomeada (Löwenstein et al., 2005). Já o uso do amitraz torna-se dificultoso devido à maioria dos gatos terem manejo difícil no banho e também ser potencialmente tóxico (Saari et al., 2009), embora sua utilização em doses terapêuticas seja segura em felinos hígidos, não diabéticos ou com cardiopatias (Andrade et al., 2007). Posteriormente, iniciou a utilização da selamectina na apresentação spot on, que se mostrou eficaz, além de fácil aplicação em gatos (Fisher \& Shanks, 2008), milbemicina $2 \mathrm{mg} / \mathrm{kg}$, via oral, em dose única (Bizikova, 2014), moxidectina subcutânea na dose de $0,2 \mathrm{mg} / \mathrm{kg}$ a cada 4 dias, associado à banhos semanais com triclosan 0,15\% (Valandro et al., 2016) e moxidectina tópica (uso semanal da formulação 10\% imidacloprid + 1\% moxidectina, durante 8 semanas, e 2 semanas posteriores à cura clínica (Short \& Gram, 2016).

O tratamento da demodicose generalizada em cães foi recentemente aprimorado pela introdução de isoxazolinas, que hoje são amplamente utilizadas como alternativa às lactonas macrocíclicas. Essas moléculas são consideradas muito seguras em mamíferos (Fourie et al., 2015; Six et al., 2016). Em um estudo em gatos, a utilização de $28 \mathrm{mg} / \mathrm{kg}$ de furalaner via oral, não causou efeitos colaterais, e, após 2 meses da administração, houve remissão dos sinais clínicos em infecção por D. cati (Matricoti \& Maina, 2017). Para o tratamento de demodiciose por D. gatoi, com o uso do mesmo princípio ativo, 26-34 $\mathrm{mg} / \mathrm{kg}$ em dose única se mostrou eficaz (Duangkaew \& Hoffman, 2018). Quando há dermatite bacteriana concomitante, a antibioticoterapia (tópica e/ou sistêmica) é recomendada e o prognóstico depende muito do estado imunológico do animal e das doenças subjacentes (Santos et al., 2009).

\section{Conclusões}

A demodiciose felina é uma dermatopatia considerada de rara ocorrência, porém na atualidade, é considerada emergente. Toda alteração cutânea que curse com prurido e/ou alopecia deve ser considerada um caso suspeito da afecção, sendo, portanto, fundamental a realização dos exames 
complementares para o correto diagnóstico, porém o diagnóstico terapêutico também possa ser considerado. Ainda, é fundamental a busca de fatores imunossupressores nos casos em que há a ocorrência do $D$. cati, e a avaliações de todos os contactantes quando há a identificação de um gato acometido por D. gatoi, principalmente para a determinação do prognóstico, o qual, no geral, é bom. Hoje em dia já existem inúmeras opções terapêuticas, e as mesmas devem ser consideradas sempre de acordo com cada paciente e com as condições do tutor. Com o avançar das pesquisas na área da dermatologia veterinária, tem surgido novas opções terapêuticas e de diagnóstico, e, muito em breve devam ser incorporados novos exames na rotina clínica. Dessa forma, é de fundamental importância que o clínico e o dermatologista de pequenos animais se mantenham atualizados e em constante aperfeiçoamento para o correto manejo de seus pacientes com alterações cutâneas.

\section{Referências bibliográficas}

Andrade, S. F., Laposy, C. B., Cardoso, C. S., Sakamoto, K. P. \& Motta, Y. P. (2007). Uso tópico do amitraz em concentração terapêutica em gatos. Ciência Rural, 37(4):1027-1032.

Beale, K. (2012). Feline demodicosis: a consideration in the itchy or overgrooming cat. Journal of Feline Medicine and Surgery, 14(3):209-213.

Bernstein, J. A., Frank, L. A. \& Kania, S. A. (2014). PCR amplification and DNA sequence identification of an unusual morphological form of Demodex cati in a cat. Veterinary Dermatology, 25(5):487-e480.

Bizikova, P. (2014). Localized demodicosis due to Demodex cati on the muzzle of two cats treated with inhalant glucocorticoids. Veterinary Dermatology, 25(3):222-225.

Carlotti, D. (2006). Demodex injai, Demodex cati and Demodex gatoi (and others...): Diagnosis and treatment. Paper presented at the Proceedings of the 21st ESVD Congress, Lisbon, Portugal.

Desch Juniorr, C. E. \& Stewart, T. B. (1999). Demodex gatoi: new species of hair follicle mite (Acari: Demodecidae) from the domestic cat (Carnivora: Felidae). Journal of Medical Entomology, 36(2):167-170.

Duangkaew, L. \& Hoffman, H. (2018). Efficacy of oral fluralaner for the treatment of Demodex gatoi in two shelter cats. Veterinary Dermatology, 29(3):262-262.

Ferreira, D., Sastre, N., Ravera, I., Altet, L., Francino, O., Bardagí, M. \& Ferrer, L. (2015). Identification of a third feline D emodex species through partial sequencing of the $16 \mathrm{~S} \mathrm{r}$ DNA and frequency of D emodex species in 74 cats using a PCR assay. Veterinary Dermatology, 26(4):239-e253.

Fisher, M. A. \& Shanks, D. J. (2008). A review of the off-label use of selamectin (Stronghold ${ }^{\circledR} /$ Revolution ${ }^{\circledR}$ ) in dogs and cats. Acta Veterinaria Scandinavica, 50(1):1-5.

Foley, R. H. (1995). Feline Demodicosis. Compendium on Continuing Education, 17481-486.

Fourie, J. J., Liebenberg, J. E., Horak, I. G., Taenzler, J., Heckeroth, A. R. \& Frénais, R. (2015). Efficacy of orally administered fluralaner (Bravecto TM) or topically applied imidacloprid/moxidectin (Advocate ${ }^{\circledR}$ ) against generalized demodicosis in dogs. Parasites \& Vectors, 28(1):1-7.

Frank, L. A., Kania, S. A., Chung, K. \& Brahmbhatt, R. (2013). A molecular technique for the detection and differentiation of D emodex mites on cats. Veterinary Dermatology, 24(3):1-5.

Guaguère, E., Olivry, T., Delverdier-Poujade, A., Denerolle, P. \& Magnol, J. P. (1999). Demodex cati infestation in association with feline cutaneous squamous cell carcinoma in situ: a report of five cases. Veterinary Dermatology, 1061-67.

Hnilica, K. A. \& Medleau, L. (2012). Dermatologia de pequenos animais: atlas colorido e guia terapêutico. Rio de Janeiro, Rio de Janeiro, Brasil. : Roca.

Iliev, P. T., Zhelev, G., Ivanov, A. \& Prelezov, P. (2019). Demodex cati and feline immunodeficiency virus co-infection in a cat. Bulgarian Journal of Veterinary Medicine, 22(2):237-242.

Johnstone, I. P. (2002). Doramectin as a treatment for canine and feline demodicosis. Australian Veterinary Practitioner, 32(3):98-103.

Kano, R., Hyuga, A., Matsumoto, J., Nogami, S., Nemoto, S., Hasegawa, A. \& Kamata, H. (2012). Feline demodicosis caused by an unnamed species. Research in Veterinary Science, 92(2):257-258. 
Lacey, N., Raghallaigh, S. N. \& Powell, F. C. (2011). Demodex mites-commensals, parasites or mutualistic organisms. Dermatology, 222(2):128-130.

Löwenstein, C., Beck, W., Bessmann, K. \& Mueller, R. S. (2005). Feline demodicosis caused by concurrent infestation with Demodex cati and an unnamed species of mite. Veterinary Record, 157290-292.

Matricoti, I. \& Maina, E. (2017). The use of oral fluralaner for the treatment of feline generalised demodicosis: a case report. Journal of Small Animal Practice, 58(8):476-479.

Medleau, L., Hnilica, K. A. \& Fagliari, G. S. (2003). Dermatologia de pequenos animais: atlas colorido e guia terapêutico. São Paulo: Roca.

Miller, W. H., Griffin, C. E., Campbell, K. L. \& Muller, G. H. (2013). Muller and Kirk's Small Animal Dermatology. Philadelphia, USA: Elsevier Health Sciences.

Moriello, K. (2014). Feline dermatophytosis: aspects pertinent to disease management in single and multiple cat situations. Journal of Feline Medicine and Surgery, 16(5):419-431.

Neel, J. A., Tarigo, J., Tater, K. C. \& Grindem, C. B. (2007). Deep and superficial skin scrapings from a feline immunodeficiency virus-positive cat. Veterinary Clinical Pathology, 36(1):101-104.

Ortúñez, A., Arribas, M. T. V., Navarro, L., Real, L. \& Vilela, C. (2009). Demodicosis felina: a propósito de tres casos clínicos. Clínica Veterinaria de Pequeños Animales, 29(3):165-171.

Pereira, S. A., Pacheco, S. T. M., Borges, F. F., Paes Leme, L. R., Barbieri, S. I., Okamoto, T., . . . Schubach, A. (2005). Demodicose associada à Esporotricose e Pediculose em gato co-infectado por FIV/FeLV. Acta Scientiae Veterinariae, 33(1):75-78.

Saari, S. A. M., Juuti, K. H., Palojärvi, J. H., Väisänen, K. M., Rajaniemi, R.-L. \& SaijonmaaKoulumies, L. E. (2009). Demodex gatoi-associated contagious pruritic dermatosis in cats-a report from six households in Finland. Acta Veterinaria Scandinavica, 51(1):1-8.

Santos, L. M., Machado, J. d. A. C. \& Neves, M. (2009). Demodicose canina: revisão de literatura. Revista Cientifica Eletrônica de Medicina Veterinária, 7(12):1-5.

Short, J. \& Gram, D. (2016). Successful treatment of Demodex gatoi with 10\% imidacloprid/1\% moxidectin. Journal of the American Animal Hospital Association, 52(1):68-72.

Silbermayr, K., Joachim, A., Litschauer, B., Panakova, L., Sastre, N., Ferrer, L. \& Horvath-Ungerboeck, C. (2013). The first case of Demodex gatoi in Austria, detected with fecal flotation. Parasitology Research, 112(8):2805-2810.

Six, R. H., Becskei, C., Mazaleski, M. M., Fourie, J. J., Mahabir, S. P., Myers, M. R. \& Slootmans, N. (2016). Efficacy of sarolaner, a novel oral isoxazoline, against two common mite infestations in dogs: Demodex spp. and Otodectes cynotis. Veterinary Parasitology, 22262-66.

Takle, G. L. \& Hnilica, K. A. (2004). Eight emerging feline dermatoses. Veterinary Medicine, 1456468.

Valandro, M. A., Pascon, J. P. E., Mistieri, M. L. A. \& Gallina, T. (2016). Demodiciose felina por Demodex cati. Acta Scientiae Veterinariae, 441-4.

Van Poucke, S. (2001). Ceruminous otitis externa due to demodex cati in a cat. Veterinary Record, 149651-652.

Wolberg, A. C. \& Blanco, A. (2008). Pruritus in the cat. Vet Focus, 18(1):4-11.

Recebido: 16 de setembro, 2019.

Aprovado: 16 de novembro, 2019.

Publicado: 31 de novembro,2019.

Licenciamento: Este artigo é publicado na modalidade acesso aberto sob a licença Creative Commons Atribuição 4.0 (CC-BY 4.0), a qual permite uso irrestrito, distribuição, reprodução em qualquer meio, desde que o autor e a fonte sejam devidamente creditados. 